

October 2021

\title{
The Prognostic Significance of Androgen Receptor Expression in Malignant Gliomas
}

\author{
Ming-yang Hung \\ University of Nebraska Medical Center \\ Nan Zhou \\ University of Nebraska Medical Center \\ Chi Zhang \\ University of Nebraska Medical Center
}

Tell us how you used this information in this short survey.

Follow this and additional works at: https://digitalcommons.unmc.edu/gmerj

Part of the Higher Education Commons, and the Medicine and Health Sciences Commons

\section{Recommended Citation}

Hung, M., Zhou, N., , Zhang, C. The Prognostic Significance of Androgen Receptor Expression in Malignant Gliomas. Graduate Medical Education Research Journal. 2021 Oct 04; 3(1).

https://digitalcommons.unmc.edu/gmerj/vol3/iss1/15

This Conference Proceeding is brought to you for free and open access by DigitalCommons@UNMC. It has been accepted for inclusion in Graduate Medical Education Research Journal by an authorized editor of DigitalCommons@UNMC.For more information, please contact digitalcommons@unmc.edu. 


\section{The Prognostic Significance of Androgen Receptor Expression in Malignant}

Gliomas

\section{Creative Commons License}

\section{c) (1)@ $\Theta$}

This work is licensed under a Creative Commons Attribution-Noncommercial-No Derivative Works 4.0 License. 
Methods: We performed a retrospective cohort study, identifying patients with gout using the VHA administrative data from $1 / 1999-9 / 2015$ based on the presence of $\geq 2$ ICD-9 codes for gout (274.X). Patients were followed from the index date until death or censoring. Potential predictors of mortality were defined using data prior to the index date. Multivariable Cox regression models were constructed to identify independent predictors of all-cause mortality.

Results: We identified 559,253 gout patients in the VHA during the study period. Over $4,250,477$ patient-years of follow-up, there were 246,291 deaths. Multivariable adjusted associations with all-cause mortality are shown in Table 1. Risk factors associated with increased mortality risk included male sex, older age, Black non-Hispanic race, comorbidities, diuretic, opioid, ULT, colchicine, and steroid use. Factors associated with a lower risk of all-cause mortality included white Hispanic, black Hispanic, and Asian races, elevated BMI, comorbid HTN, and NSAID use.

Conclusion: We have preliminarily identified multiple risk factors for mortality in veterans with gout with the strongest risk factors being comorbid CVD, diabetes, lung disease, and cancer, as well as the use of steroids and opioids. Mechanisms underpinning associations between select medication use and survival will require additional study accounting for the effects of comorbid CKD is this CKD or CVD and measures of gout severity.

https://doi.org/10.32873/unmc.dc.gmerj.3.1.036
Table 1.

Patient characteristics associated with all-cause mortality in veterans with gout.

\begin{tabular}{|c|c|}
\hline Characteristic & Adjusted HR $(95 \% \mathrm{Cl})^{*}$ \\
\hline \multicolumn{2}{|l|}{ Demographics } \\
\hline Age, Years & $1.06(1.06,1.06)$ \\
\hline Male (vs. Female) Sex & $1.07(1.02,1.12)$ \\
\hline $\begin{array}{l}\text { Race and Ethnicity } \\
\text { White Hispanic } \\
\text { White Non-Hispanic } \\
\text { Black Hispanic } \\
\text { Black Non-Hispanic } \\
\text { Asian } \\
\text { Other } \\
\text { Missing }\end{array}$ & $\begin{array}{l}0.81(0.78,0.83) \\
\text { Referent } \\
0.78(0.69,0.89) \\
1.06(1.04,1.07) \\
0.62(0.59,0.66) \\
1.07(1.04,1.09) \\
1.95(1.93,1.97)\end{array}$ \\
\hline Service Connected Condition & $0.84(0.83,0.85)$ \\
\hline Urban Residence (vs. Rural) & $1.02(1.02,1.03)$ \\
\hline VHA Enrollment Duration, Years & $0.95(0.95,0.95)$ \\
\hline \multicolumn{2}{|l|}{ Health Factors \& Comorbidities } \\
\hline $\begin{array}{l}\text { Body Mass Index } \\
<20 \mathrm{~kg} / \mathrm{m} 2 \\
20 \text { to }<25 \mathrm{~kg} / \mathrm{m} 2 \\
25 \text { to }<30 \mathrm{~kg} / \mathrm{m} 2 \\
\geq 30 \mathrm{~kg} / \mathrm{m} 2\end{array}$ & $\begin{array}{l}0.97(0.93,1.02) \\
\text { Referent } \\
0.74(0.73,0.75) \\
0.68(0.67,0.69)\end{array}$ \\
\hline $\begin{array}{l}\text { Comorbidities } \\
\text { Myocardial infarction or atherosclerosis, \% } \\
\text { Other cardiovascular disease, \% } \\
\text { Stroke, \% } \\
\text { Hypertension, \% } \\
\text { Lung disease, \% } \\
\text { Depression, \% } \\
\text { Diabetes mellitus, \% } \\
\text { Ulcer or stomach problem, \% } \\
\text { Cancer, \% }\end{array}$ & $\begin{array}{l}1.11(1.09,1.13) \\
1.46(1.45,1.47) \\
1.17(1.15,1.19) \\
0.90(0.89,0.91) \\
1.59(1.57,1.61) \\
1.15(1.14,1.17) \\
1.34(1.32,1.35) \\
1.06(1.04,1.08) \\
1.23(1.21,1.24)\end{array}$ \\
\hline Diuretic Use & $1.37(1.36,1.39)$ \\
\hline \multicolumn{2}{|c|}{ Gout Disease Characteristics and Medication Use } \\
\hline $\begin{array}{l}\text { ULT Use (Allopurinol, Febuxostat, Probenecid, } \\
\text { Pegloticase) }\end{array}$ & $1.04(1.03,1.05)$ \\
\hline NSAID Use & $0.87(0.86,0.88)$ \\
\hline Steroid Use & $1.15(1.13,1.16)$ \\
\hline Colchicine Use & $1.08(1.07,1.09)$ \\
\hline Opioid Use & $1.17(1.16,1.19)$ \\
\hline$\geq 1$ Serum Urate Test During Prior Year & $0.99(0.98,1.00)$ \\
\hline
\end{tabular}

*All variables included in multivariable model are shown in the table

Abbreviations: VHA, Veterans Health Administration; ULT, urate lowering therapy

\section{The Prognostic Significance of Androgen Receptor Expression in Malignant Gliomas Ming-yang Hung ${ }^{1}$, Nan Zhou', Chi Zhang ${ }^{1}$}

${ }^{1}$ University of Nebraska Medical Center, College of Medicine, Department of Radiation Oncology

\section{Mentor: Chi Zhang}

Program: Radiation Oncology

Type: Original Research

Background: Androgen receptor (AR) overexpression has been identified in malignant gliomas, suggesting that AR plays an important role in tumor carcinogenesis. However, the prognostic significance of AR overexpression remains largely to be explored.
Methods: AR gene expression at the levels of mRNA, protein expression, and clinical data were obtained from the Cancer Genome Atlas (TCGA) and Chinese Glioma Genome Atlas (CGGA) databases. AR expression levels were compared across gliomas of different histopathologic and molecular subtypes. Lastly, Kaplan-Meier survival analyses in patients with different AR expression levels were investigated for the potential prognostic values of $A R$.

Results: Compared to normal brain tissue, malignant gliomas showed significantly higher AR mRNA expression $(\mathrm{p}<.01)$.

Furthermore, AR mRNA expression was more prominent in higher grade disease, regardless of histopathologic and molecular subtypes $(p<0.01)$. Similarly, at the protein level, AR protein was more abundant in GBM than in lower grade gliomas (LGG) (grade II and III) $(\mathrm{p}<0.0001)$. This was corroborated by a linear association between AR mRNA and protein expression $(r=0.65, p<0.001)$. Finally, in LGG, both high AR gene and protein expression were associated with significantly worse overall survival. Five-year overall survival for patients with LGG with high AR 
gene expression and low AR gene expression were $59.1 \%$ and $73.3 \%$ respectively ( $\mathrm{p}$ $<0.0001)$. Gender did not appear to be associated with either AR gene expression or prognosis.

Conclusions: AR gene overexpression is frequent in malignant gliomas and correlates with increased protein expression. Higher AR expression levels are associated with higher grade disease and histopathologic features predicting poorer prognosis. Furthermore, high gene expression in LGG is correlated with poor prognosis but not within GBM, indicating saturated expression/functions of
AR in GBM. It will be important to evaluate AR gene and protein status to properly interpret future clinical trials using AR inhibitors.

https://doi.org/10.32873/unmc.dc.gmerj.3.1.037

\section{The Effect and Utility of Emergency Medicine Residency Orientation} Nicholas Jobeun ${ }^{1}$, Chad Branecki ${ }^{1}$, Elizabeth Lyden ${ }^{2}$, Aaron Barksdale $^{1}$

${ }^{1}$ University of Nebraska Medical Center, College of Medicine, Department of Emergency Medicine ${ }^{2}$ University of Nebraska Medical Center, College of Public Health

Mentor: Chad Branecki

Program: Emergency Medicine

Type: Original Research

Background: Most matriculating emergency medicine (EM) postgraduate year-ones (PGY$1 \mathrm{~s})$ receive a form of orientation to acclimate them to residency. With varying medical school education and clinical experiences, the orientation month is used to provide equal preparation for all PGY-1s. Educational best practices have yet to be identified for a universal curriculum despite the longstanding history of residency orientation. The objectives of this study were to determine the benefits of EM residency orientation and identify areas of improvement for future curriculum development.

Methods: In July 2020, 12 PGY-1s underwent their EM orientation month, which included lectures, self-study, procedure skills labs, and simulation. Pre- and post-orientation surveys were administered and assessed for perceived comfort with common EM skills, preferred instructional methods, and the effect orientation had on their medical knowledge. For quantitative analysis, a 100-question EM board style exam was given at the beginning and end of the month. Data were summarized with descriptive statistics. Analysis was done using Spearman correlation coefficients, the Wilcoxon signed-rank test, and the Mann-Whitney test. A P-value $<0.05$ was considered statistically significant.

Results: The pre- and post-survey and exam completion was $100 \%$ (12 of 12 PGY-1s). There was a statistically significant difference $(p<0.0005)$ in the perceived benefit of the orientation month. Pharmacology (91.7\%) and EMR documentation (66.7\%) were identified as the largest knowledge gaps prior to residency. Skills labs $(91.7 \%)$ and simulation $(58.3 \%)$ were identified as the most effective instructional methods. There was a statistically significant $(\mathrm{p}<$ 0.05 ) improvement in perceived comfort performing ultrasounds, sutures, splints, central venous catheters (CVC), lumbar punctures (LP), intubations, donning of personal protective equipment (PPE), and interpretation of electrocardiograms (EKG) and computed tomography (CT).

Conclusion: The use of a residency orientation for EM PGY-1s improved the perceived comfort for beginning residency. Interactive instructional methods (skills labs and simulation) were perceived as more effective in learning, compared to lecturebased instruction.

https://doi.org/10.32873/unmc.dc.gmerj.3.1.039

\section{Alexander Sawatzke ${ }^{1}$, Justin C. Siebler ${ }^{1}$, Matthew A. Mormino ${ }^{1}$ \\ ${ }^{1}$ University of Nebraska Medical Center, College of Medicine, Department of Orthopedic Surgery 2Optum Orthopedics, Covina, California \\ ${ }^{3}$ University of Utah, Department of Orthopedic Surgery \\ ${ }^{4}$ Ohio University, Wexner Medical Center, Department of Anesthesiology \\ ${ }^{5}$ University of Nebraska Medical Center, College of Public Health, Department of Biostatistics}

Patterns of Opiate Prescription Practices in Isolated Operative Ankle Fractures: Creating Guidelines David J. Kusin'1, Ryan E. Miller², Zachary Bailey', Erin Stockwell', Emily A. Boes ${ }^{3}$, Colton Roessner ${ }^{4}$, Kaeli K. Samson ${ }^{5}$, Sara M. Putnam¹,

Mentor: Justin Siebler

Program: Orthopedic Surgery

Type: Original Research

Background: Opioid use is associated with significant morbidity and safer alternatives to pain control exist. The purpose of this study was to quantify our opioid prescribing practices for isolated, operative ankle fractures and to formulate guidelines for safe and effective opioid stewardship.

Methods: The baseline average quantity of opioids prescribed (as Morphine Milligram Equivalents) at discharge and in the 90 days after surgery for adults with operatively treated, isolated ankle fractures were determined and prescribing guidelines were implemented. Opioid use was correlated to patient demographics, comorbidities, fracture characteristics, and patient reported pain control in each group.

Results: The baseline and test groups had 37 (24 female, 13 male) and 34 (21 female, 13 male) patients, respectively. There was no significant difference in age (49.7 vs. 47.2 years), comorbidities, or open fractures (1 vs 3). The mean MME prescribed was 444.86 $($ stdev $=314.9$, range $=0-1425)$, versus $361.5($ stdev 232.9 , range $=112.5-1025)$. This $18.8 \%$ reduction was not statistically significant $(p=0.32)$. There was no difference in pain scores at the first or second postoperative visits (2.64 vs 2.84 and 1.56 vs 1.81 ). There was no correlation between patient demographics, comorbidities, or fracture characteristics and MME prescribed or pain scores. Patients with higher pain scores at the first visit had more MME prescribed $(\mathrm{p}=0.02$ and 0.03$)$.

Conclusion: Postoperative opioid use in isolated, operative ankle fractures in adult patients was reduced without a significant difference in patient reported pain control, but the decrease was not statistically significant.

https://doi.org/10.32873/unmc.dc.gmerj.3.1.033 